\title{
Trends in Sports Results of the Strongest Athletes
}

\author{
Martynova V.A. \\ Kuban State University of Physical Culture, Sports and Tourism \\ viktoria2580@mail.ru
}

\begin{abstract}
In the presented work the tendency of foreign and domestic athletes' sports results development in the period 2016-2018 is considered. The comparative data given for the 3year period, on the main parameters such as: average age of participants, individual achievements, number of starts in this period are presented. When considering individual achievements, the number of starts in this period were revealed: the dynamics of personal results in the shot put in athletes for three years have a positive trend, but the results of domestic shot putters in three years of dynamics are not stable. The article also discusses the number of starts in three-year period, which shows that foreign athletes in planning the training process, put the emphasis on performance in the summer season, and the number of starts is much higher than that of domestic athletes. Comparative data of world and Russian leaders achievements are given, the expected tendencies of their change in the next years are shown.
\end{abstract}

Keywords-athletics; ranking; world achievements.

\section{INTRODUCTION}

In recent years, competition in the international sports arena grew significantly. Among Russian athletes there are a large number of world and Olympic Champions [1]. However, in recent years, against the background of the global political situation, Russian athletes are discredited in the media, persecuted by international sports organizations, and most sadly-unsubstantiated accusations and falsifications of the tests results for the use of doping drugs $[1,3]$.

In the sports world, Russian track and field athletes were denied entry to the 2017 World Championship and the summer Olympics in Rio de Janeiro. Negative trends in relation to Russian athletes at the international level, cannot but affect the internal development of athletics in Russia. Professional athletes who go all their lives to global goals in their careers (victories at the World Championships, in the Olympic games) are deliberately deprived of the opportunity to participate and win personal victories at world competitions due to bias towards our country. This can negatively affect the development of professional athletics and contribute to the outflow of capable athletes starting their careers in Western countries, where there will be no barriers to their performances at the international level, or moving to practice athletics in other sports $[1,2]$.
In this situation, there is a need for a serious analysis of the factors that can determine the level of sports achievements, as well as those necessary for the training of specialists in this field $[4,5,6,7,8,9]$.

\section{LITERATURE REVIEW}

The analysis of scientific and methodical literature shows that immeasurably increased requirements to the level and reliability of highly qualified athletes, huge amounts of training and competitive loads and the increasing struggle with the use of ethically and valeologically unacceptable ways to improve the level of sports performance have largely caused in recent years the need to find new ways to solve these problems in the theory and methodology of training. At the same time, from the methodological standpoint of modernity, there is an urgent need for fundamental research related to the complex individualization of training and competitive activity of high-class athletes, which allows to constructively increase the efficiency of their training $[3,10,11,12]$.

\section{RESEARCH METHOdOlOgy}

The purpose of our research is a comparative analysis of the successful performance of foreign and Russian athletes in recent years.

Methodology and organization of research: analysis of scientific and methodological literature; systematization and analysis of scientific and methodological literature and normative legal acts devoted to the problem of research; analysis of statistical reports and protocols of international competitions in athletics, top lists of athletes;

Mathematical and statistical processing: to restore the significant differences between the performance of elite athletes was used indicator of the average value. Data processing was carried out on a computer in a Microsoft Excel environment.

As part of our study, we conducted a comparative analysis of the world results of athletes competing in the shot put in the period 201620182018.

The practical significance of the research results lies in the possibility of applying the results obtained by the athletics Federation in the preparation of target programs for training foreign and Russian athletes for the upcoming competitions. 


\section{RESULTS}

As part of our study, we conducted a comparative analysis of age differences between the best domestic and foreign athletes competing in this sport in 2016-2018 [1].

The analysis of age features showed, data, reliable age differences at domestic and foreign athletes in men in 20162018 are not revealed. In 2016, the age of participants in domestic male athletes was $26.10 \pm 2.80$ years, in foreign athletes this indicator was $26.12 \pm 2.72$ years. In the process of studying 2017, 2018. the difference between domestic and foreign athletes is not significant $201827.50 \pm 3.50$ in domestic and $27.90 \pm 2.64$ in foreign athletes.

The analysis of the age indicator in male pushers shows that the peak results fall on 26-27 years., it should be noted that there are domestic athletes competing for many years since 2005 on the world stage, whose age exceeds the average among pushers (32 years).

The next stage of the work was devoted to the average results analysis of the best domestic and foreign shot putters in men and women in the same time range with differentiation for winter and summer starts (table 1).
The analysis of domestic athlete's dynamics indicators in men within three years showed that the average value varies both in positive dynamics, and in negative one. In the comparison process results of leading athletes in this kind of sport for 2016 shows, that ten best of countries athletes the average outcome from $20.21 \pm 0.72 \mathrm{~m}$ until $17 \pm 86 \pm 0.36 \mathrm{~m}$. The number of starts is in average 8-10 a year. In foreign leaders, this figure is much higher $21.36 \pm 0.79 \mathrm{~m}$ and $19.47 \pm 0.63 \mathrm{~m}$.

At the same time, it should be noted that the increase in starts in 2017 among Russian male athletes leads to a positive trend of performance in $85 \%$ of athletes. So in $2018,70 \%$ of the considered pushers had a positive trend, 4 athletes, leaders of the season performed the result $20 \mathrm{~m}$. It should be noted that the number of Russian athletes starts during the three summer seasons does not change much.

In the process of comparative analysis between Russian and foreign athletes, we found that in the 20172018 seasons, the number of starts for many athletes reaches more than 15 , which naturally has a positive effect on the performance of athletes. It 2018, the average indicator of individual achievements are in the range of $21-22 \mathrm{~m}$. Data are presented in table

TABLE I. SUMMARY TABLE OF AVERAGE AND BEST INDIVIDUAL ACHIEVEMENT OF RUSSIAN AND FOREIGN MALE ATHLETES

\begin{tabular}{|c|c|c|c|c|c|c|c|c|c|}
\hline \multirow{2}{*}{$\begin{array}{c}\text { № } \\
\text { participants }\end{array}$} & \multicolumn{3}{|c|}{2016} & \multicolumn{2}{|c|}{2017} & \multirow[b]{2}{*}{$\begin{array}{l}\text { number } \\
\text { of starts }\end{array}$} & \multicolumn{2}{|c|}{2018} & \multirow[b]{2}{*}{$\begin{array}{l}\text { number } \\
\text { of starts }\end{array}$} \\
\hline & average result & $\begin{array}{c}\text { individual } \\
\text { achievement }\end{array}$ & $\begin{array}{l}\text { number } \\
\text { of starts }\end{array}$ & average result & $\begin{array}{c}\text { individual } \\
\text { achievement }\end{array}$ & & average result & $\begin{array}{c}\text { individual } \\
\text { achievement }\end{array}$ & \\
\hline \multicolumn{10}{|c|}{ Russian athletes } \\
\hline 1 & $20,21 \pm 0,72$ & 20,96 & 5 & $20,55 \pm 0,47$ & $21,04 *$ & 15 & $20,32 \pm 0,51$ & $21,39 *$ & 14 \\
\hline 2 & $19,81 \pm 0,25$ & 20,04 & 13 & $19,85 \pm 0,36$ & $20,44 *$ & 14 & $20,01 \pm 0,58$ & $20,88^{*}$ & 11 \\
\hline 3 & $19,53 \pm 0,62$ & 20,53 & 12 & $19,07 \pm 0,42$ & 19,56 & 6 & $19,14 \pm 0,31$ & 19,42 & 3 \\
\hline 4 & $20,23 \pm 0,47$ & 21,03 & 11 & $20,51 \pm 0,57$ & $21,36^{*}$ & 15 & $20,93 \pm 0,52$ & $21,58^{*}$ & 14 \\
\hline 5 & $18,69 \pm 0,33$ & 19,31 & 9 & $18,66 \pm 0,25$ & 19,11 & 14 & $18,25 \pm 0,31$ & 18,77 & 8 \\
\hline 6 & $17,93 \pm 0,51$ & 18,68 & 6 & $18,65 \pm 0,58$ & $19,47^{*}$ & 9 & $18,23 \pm 0,34$ & 18,69 & 9 \\
\hline 7 & $17,86 \pm 0,36$ & 17,91 & 6 & $18,37 \pm 0,28$ & $18,83^{*}$ & 5 & $19,05 \pm 0,89$ & $20,01^{*}$ & 4 \\
\hline 8 & нет & нет & 1 & $16,76 \pm 0,57$ & $17,35^{*}$ & 7 & $18,13 \pm 0,64$ & $18,86^{*}$ & 3 \\
\hline 9 & $18,89 \pm 0,49$ & 19,56 & 12 & $18,77 \pm 0,51$ & $19,67 *$ & 12 & $18,22 \pm 0,26$ & 18,58 & 7 \\
\hline 10 & $18,81 \pm 0,55$ & 19,4 & 3 & $18,11 \pm 0,62$ & 19,0 & 10 & $17,79 \pm 0,41$ & 18,08 & 2 \\
\hline \multicolumn{10}{|c|}{ Foreign athletes } \\
\hline 1 & $21,36 \pm 0,79$ & 22,52 & 16 & $21,99 \pm 0,50$ & 22,47 & 15 & $22,35 \pm 0,43$ & $22,53 *$ & 12 \\
\hline 2 & $20,50 \pm 0,63$ & 21,63 & 16 & $21,02 \pm 0,57$ & $22,44^{*}$ & 16 & $21,04 \pm 0,61$ & 21,72 & 20 \\
\hline 3 & $19,47 \pm 0,43$ & 20,11 & 14 & $19,97 \pm 0,42$ & $20,69 *$ & 11 & $20,53 \pm 0,61$ & $21,63^{*}$ & 15 \\
\hline 4 & $21,26 \pm 0,67$ & 22,13 & 13 & $21,36 \pm 0,76$ & $22,57^{*}$ & 9 & $20,57 \pm 0,31$ & 21,02 & 6 \\
\hline 5 & $22,21 \pm 0,47$ & 22,21 & 14 & $21,69 \pm 0,38$ & 22,14 & 14 & $21,70 \pm 0,56$ & $22,67 *$ & 7 \\
\hline 6 & $20,24 \pm 0,61$ & 21,35 & 24 & $20,72 \pm 0,65$ & $21,88^{*}$ & 25 & $21,38 \pm 0,35$ & $22,08^{*}$ & 24 \\
\hline 7 & $20,73 \pm 0,40$ & 21,39 & 14 & $20,37 \pm 3,89$ & $21,87^{*}$ & 26 & $21,13 \pm 0,36$ & 21,62 & 19 \\
\hline 8 & $20,06 \pm 0,73$ & 20,82 & 9 & $20,68 \pm 0,71$ & $21,29 *$ & 17 & $20,38 \pm 0,44$ & 21,02 & 14 \\
\hline 9 & $20,23 \pm 0,67$ & 21,26 & 15 & $21,22 \pm 0,53$ & $22,01 *$ & 25 & $21,34 \pm 0,40$ & $22,17^{*}$ & 16 \\
\hline
\end{tabular}

In women the dynamics of domestic athletes' achievements for three years showed that the average value varies as well as in men in positive dynamics, and in negative one. Process comparison women results for 2016 shows, ten of best country athletes is the average results from $15,08 \pm 0,31 \mathrm{~m}$ to $17,92 \pm 0,42 \mathrm{~m}$. The number of starts is $8-10$ a year, also as Russian athletes have. In foreign 
leaders, this figure is much higher $16.36 \pm 0.35 \mathrm{~m}$ and $19.67 \pm 0.36 \mathrm{~m}$

It should be noted that women do not such a large number of starts as men have.

In the process of comparative analysis among athletes, Russian and foreign athletes, we found that in 2017-2018 2018 seasons, the number of starts for many Russian athletes was within 8-10 starts and the performance of athletes fluctuates in the average of 17 meters. In foreign athletes, the frequency of competitive activity increases to
18 starts per year and the performance ranges from $16.55 \pm 0.94 \mathrm{~m}$ to $19.20 \pm 0.65 \mathrm{~m}$.

In 2018, the average rate of four Russian athletes' individual achievements has a positive trend, but $60 \%$ of it remains unchanged at the level of 2017. In foreign athletes in 2018, a sharp increase in the number of starts and performance is $17.03 \pm 1.87 \mathrm{~m}-19.58 \pm 0.52 \mathrm{~m}$.

The comparative analysis of women in this sport shows that the Russian athletes - women, considerably concede to foreign athletes-women in this type of athletics. The data are presented in table II.

TABLE II. SUMMARY TABLE OF AVERAGE AND BEST INDIVIDUAL ACHIEVEMENT OF RUSSIAN AND FOREIGN FEMALE ATHLETES

\begin{tabular}{|c|c|c|c|c|c|c|c|c|c|}
\hline \multirow[t]{2}{*}{ № participants } & \multicolumn{3}{|c|}{2016} & \multicolumn{2}{|c|}{2017} & & \multicolumn{2}{|c|}{2018} & \multirow[b]{2}{*}{$\begin{array}{l}\text { number } \\
\text { of starts }\end{array}$} \\
\hline & average result & $\begin{array}{c}\text { individual } \\
\text { achievement }\end{array}$ & $\begin{array}{l}\text { number } \\
\text { of starts }\end{array}$ & average result & $\begin{array}{c}\text { individual } \\
\text { achievement }\end{array}$ & & average result & $\begin{array}{c}\text { individual } \\
\text { achievement }\end{array}$ & \\
\hline \multicolumn{10}{|c|}{ Russian athletes } \\
\hline 1 & $17,21 \pm 0,32$ & 17,8 & 10 & $17,34 \pm 0,46$ & 18,06 & 18 & $17,61 \pm 0,39$ & $18,16^{*}$ & 9 \\
\hline 2 & $17,92 \pm 0,42$ & 18,78 & 10 & $17,62 \pm 0,14$ & 17,88 & 8 & $17,80 \pm 0,27$ & $18,28^{*}$ & 10 \\
\hline 3 & $17,26 \pm 0,57$ & 17,67 & 2 & $17,46 \pm 0,51$ & $18,05^{*}$ & 3 & $17,51 \pm 0,32$ & 17,78 & 3 \\
\hline 4 & $17,36 \pm 0,76$ & $18,50 *$ & 11 & $17,37 \pm 0,17$ & 18,00 & 11 & $17,24 \pm 0,24$ & 17,68 & 9 \\
\hline 5 & $16,76 \pm 0,63$ & $17,45^{*}$ & 8 & $16,97 \pm 0,47$ & 17,76 & 11 & $16,29 \pm 0,80$ & 16,94 & 8 \\
\hline 6 & $16,46 \pm 0,22$ & 16,80 & 9 & $16,64 \pm 0,48$ & $17,38^{*}$ & 13 & $16,36 \pm 0,29$ & 16,69 & 9 \\
\hline 7 & $14,39 \pm 0,49$ & 15,16 & 9 & $14,93 \pm 0,38$ & 15,48 & 11 & $15,43 \pm 0,53$ & $16,51 *$ & 12 \\
\hline 8 & $16,19 \pm 0,29$ & 16,44 & 2 & $16,31 \pm 0,31$ & $16,53^{*}$ & 2 & $16,19 \pm 0,29$ & 16,44 & 4 \\
\hline 9 & $15,08 \pm 0,31$ & 15,08 & 1 & $14,70 \pm 0,66$ & 15,82 & 10 & $15,54 \pm 0,48$ & $16,31^{*}$ & 10 \\
\hline 10 & $16,18 \pm 0,78$ & 17,22 & 6 & $17,13 \pm 0,28$ & $17,51^{*}$ & 7 & $15,98 \pm 0,34$ & 16,36 & 5 \\
\hline \multicolumn{10}{|c|}{ Foreign athletes } \\
\hline 1 & $19,21 \pm 0,78$ & 19,74 & 11 & $19,20 \pm 0,65$ & 20,11 & 13 & $19,58 \pm 0,52$ & $20,38^{*}$ & 13 \\
\hline 2 & $19,43 \pm 0,45$ & $20,17 *$ & 17 & $19,08 \pm 0,86$ & 20,14 & 17 & $19,19 \pm 0,39$ & 19,78 & 19 \\
\hline 3 & $18,43 \pm 0,72$ & 19,33 & 22 & $18,65 \pm 0,64$ & $19,76^{*}$ & 14 & $19,037 \pm 0,59$ & 19,74 & 12 \\
\hline 4 & $16,36 \pm 0,35$ & 16,85 & 15 & $17,38 \pm 0,34$ & 17,72 & 13 & $18,80 \pm 0,44$ & $19,46^{*}$ & 16 \\
\hline 5 & $17,57 \pm 0,93$ & 18,63 & 10 & $17,62 \pm 0,28$ & 18,24 & 20 & $18,64 \pm 0,34$ & $19,38^{*}$ & 23 \\
\hline 6 & $17,14 \pm 0,32$ & 17,6 & 5 & $18,18 \pm 0,57$ & 19,15 & 14 & $18,33 \pm 0,56$ & $19,36^{*}$ & 16 \\
\hline 7 & $19,67 \pm 0,36$ & $20,42 *$ & 9 & нет & нет & 0 & $18,50 \pm 0,47$ & 18,50 & 15 \\
\hline 8 & $17,62 \pm 0,68$ & 18,28 & 13 & $16,55 \pm 0,94$ & 17,76 & 11 & $17,03 \pm 1,87$ & $19,23 *$ & 11 \\
\hline 9 & $17,94 \pm 0,37$ & 18,78 & 17 & $18,18 \pm 0,43$ & 19,01 & 12 & $18,79 \pm 0,30$ & $19,21^{*}$ & 14 \\
\hline 10 & $18,41 \pm 0,75$ & $19,87^{*}$ & 30 & $18,56 \pm 0,50$ & 19,49 & 26 & $18,15 \pm 0,98$ & 19,62 & 14 \\
\hline
\end{tabular}

\section{DISCUSSION}

As a result of the world and Russia strongest athletes results analysis and the forecast for the coming years, we can say with confidence that if current trends continue in the near future, we can expect:

- growth of results in shot put among men (first of all in the world as a whole, it is very likely that also in Russia) and also with a slightly higher probability-growth of results in throwing among women (also in the world as a whole and Russia).

- maintaining the leading positions of the United States (men and women) in the shot put.

Based on our research, it can be argued that in general, in the throwing disciplines of athletics, the efforts of russian specialists are now very effective, and in the training of women, the priority is more significant. This picture is a reflection of the global trend-a clear division of athletics into men's and women's with their specific effective methodological approaches to training. The approaches used by domestic specialists are generally much more effective in relation to athletes-women than to athletes-men, because they are based on the predominant emphasis on strength training. Such a line in women's athletics is still quite productive and is largely forced, since a tangible natural advantage in the speed qualities of the strongest athletes can be compensated only by power and technical work, which is often possible.

Such an approach, which combines both advanced methods of training athletes and the world's best sports talents, in our opinion, will be able to bring the domestic 
athletics school of throwing to an unattainable high level, to ensure sustainable leadership of our country in these disciplines of athletics. However, such approaches are valid not only for athletics, but also for the whole sport of higher achievements in general, but this is a question of another study.

\section{CONCLUSION}

Analysis of the Russian and foreign pushers' performance shows that the dynamics of results in men and women in the study period is not always positive. The difference between the athletes from the Russian national team and foreign athletes is within one meter, both in the men's and women's shot put.

In the course of the study, we found that the results of the leading athletes over the past 3 years do not reach the peak of the world record. We have revealed the contradiction that the age of athletes is favorable, but this tendency is not effective, therefore, it is necessary to search for effective methodological approaches to the training of high-level pushers.

\section{References}

[1] Voronina V. T. On the development of athletics in Russia. Karelian scientific journal. 2017, vol. 6, 4(21).

[2] Martynova V. A. Analysis of performances of leading foreign and domestic shot putters. In the collection: actual problems and modern tendencies of development of athletics in Russia and in the world materials of the all-Russian scientific and practical conference with the international participation devoted to memory of Professor G. V. Tsyganov. Kazan. 2019, pp. 274-277.

[3] Svublevsky, E.P. Construction of a year cycle of preparation of women in speed-power types of athletics. Scientific Sports Bulletin. 2001, 3 pp. 67-75.

[4] Martynova V.A., Cherednichenko M.V., Kuzmina V.V. Tendencies of change of sports results of the strongest shot putters of the world. In the collection: fundamental and applied research: current issues, achievements and innovations collection of articles XXV International scientific and practical conference: 2 hours. Penza. 2019, pp. 229-232.

[5] Sharifullina S.R., Zhestkova Yu.K., Martynova V.A. Educational provisions on formation of competence of management of process of physical education and sports at future teachers of physical culture theory and practice of physical culture. 2018, 3, pp. 12

[6] International Association of athletics federations. URL: https://www.iaaf.org/home

[7] Holloszy J.O. Regulation of carbohydrate metabolism during exercise: new ideas and remaining mysteries. Biochemistry of exercise. Human Kinetics Publ. 1996, pp. 3-12.

[8] Minotti D.Y., K.E. Yunson, Hydson T.L., D.V. Ala. Training of induced skeletal muscle adaptations does not depend on systemic adaptations. J. Appl. Physiology. 1990, vol. 68, 1, pp. 289-294.

[9] Clarke G., Humberstone B. The study of women and sport. London: MACMILLAN PRESS LTD. 1997, 220.

[10] Sanders R. Five components of sprint on $100 \mathrm{~m}$. The modern athlete and the trainer. 2004, 4, pp. 23-24.

[11]Alexsandr S. Kuznetsov. Russian Professor's meeting. Russian Journal of Physical Education and Sport. 2019, 14(1), pp. 17-22. DOI 10.14526/2070-4798-2019-14-1-18-24

[12] Tidou G. Aspects of strength training in athletics. New research in athletics. 1990, I, pp. 93-100. 